\title{
Biomimetic Materials by Freeze Casting
}

\author{
MICHAEL M. PORTER, ${ }^{1,4}$ JOANNA MCKITTRICK, ${ }^{1,2}$ \\ and MARC A. MEYERS ${ }^{1,2,3}$ \\ 1.-Materials Science and Engineering Program, University of California, San Diego, 9500 Gil- \\ man Drive, La Jolla, CA 92093, USA. 2.-Department of Mechanical and Aerospace Engineering, \\ University of California, San Diego, 9500 Gilman Drive, La Jolla, CA, USA. 3.-Department of \\ NanoEngineering, University of California, San Diego, 9500 Gilman Drive, La Jolla, CA, USA. \\ 4.—e-mail: m1porter@ucsd.edu
}

Natural materials, such as bone and abalone nacre, exhibit exceptional mechanical properties, a product of their intricate microstructural organization. Freeze casting is a relatively simple, inexpensive, and adaptable materials processing method to form porous ceramic scaffolds with controllable microstructural features. After infiltration of a second polymeric phase, hybrid ceramic-polymer composites can be fabricated that closely resemble the architecture and mechanical performance of natural bone and nacre. Inspired by the narwhal tusk, magnetic fields applied during freeze casting can be used to further control architectural alignment, resulting in freeze-cast materials with enhanced mechanical properties.

\section{INTRODUCTION}

Biomimetic materials are synthetic materials that mimic one or more aspects of the design, function, or properties of natural biological materials. ${ }^{1-3}$ Many structural biological materials, such as bone and abalone nacre, have evolved exceptional mechanical properties in spite of the relatively weak material constituents that make up their composition. ${ }^{1-3}$ Interestingly, their mechanical properties are highly anisotropic, an adaptation to the nature and magnitude of external tractions. ${ }^{1-3}$ These properties are a product of their complex structural organization and architectural hierarchy from the nanoscale to macroscale. ${ }^{1-3}$

A variety of materials processing methods, ranging from self-assembly ${ }^{4-6}$ and layer-by-layer deposition $^{7,8}$ to nanolithography ${ }^{9,10}$ and 3-D printing, ${ }^{11-13}$ has been explored to develop synthetic biomimetic materials. Freeze casting is a relatively simple, inexpensive, and adaptable technique to fabricate bulk porous scaffolds and hybrid composites. Deville, ${ }^{14}$ Gutierrez et al., ${ }^{15}$ Qian and Zhang, ${ }^{16}$ and $\mathrm{Li}$ et al. ${ }^{17}$ provide excellent reviews of general freeze casting topics, including the processing principles, materials, structures, properties, and applications. This article focuses on freeze casting as it relates to different biomimetic materials and processing modifications inspired by nature.
Freeze casting, also known as ice templating or freeze gelation, is commonly used to form a variety of polymeric, metallic, ceramic, and composite materials with excellent microstructural control. ${ }^{14-17}$ Figure 1 shows the basic processing steps involved in freeze casting porous ceramic scaffolds and hybrid ceramic-polymer composites-the main focus of this article. First, a liquid slurry containing ceramic powders and a freezing vehicle (e.g., water) is mixed with a dispersant (e.g., surfactant) and binder (e.g., long-chain polymer), which aid in colloid dispersion and green body integrity, respectively (Fig. 1a). Second, the liquid slurry is poured into a mold and frozen (Fig. 1b). During solidification, particles are pushed between and trapped within the freezing vehicle as it forms columnar channels of frozen solvent crystals. Third, the frozen sample is lyophilized (or freeze dried) to sublimate the frozen liquid phase (Fig. 1c). The resulting pores of the freeze-cast scaffolds after freeze drying are direct replicas of the frozen ice crystals. ${ }^{14}$ Fourth, the dried green body is sintered to partially densify and strengthen the porous ceramic constructs (Fig. 1d). The sintered scaffolds are composed of a continuous network of dense ceramic walls, surrounding interconnected channels with open porosity. ${ }^{18}$

To fabricate hybrid composites, polymers or metals may be infiltrated into the porous ceramic scaffolds. ${ }^{19-22}$ 

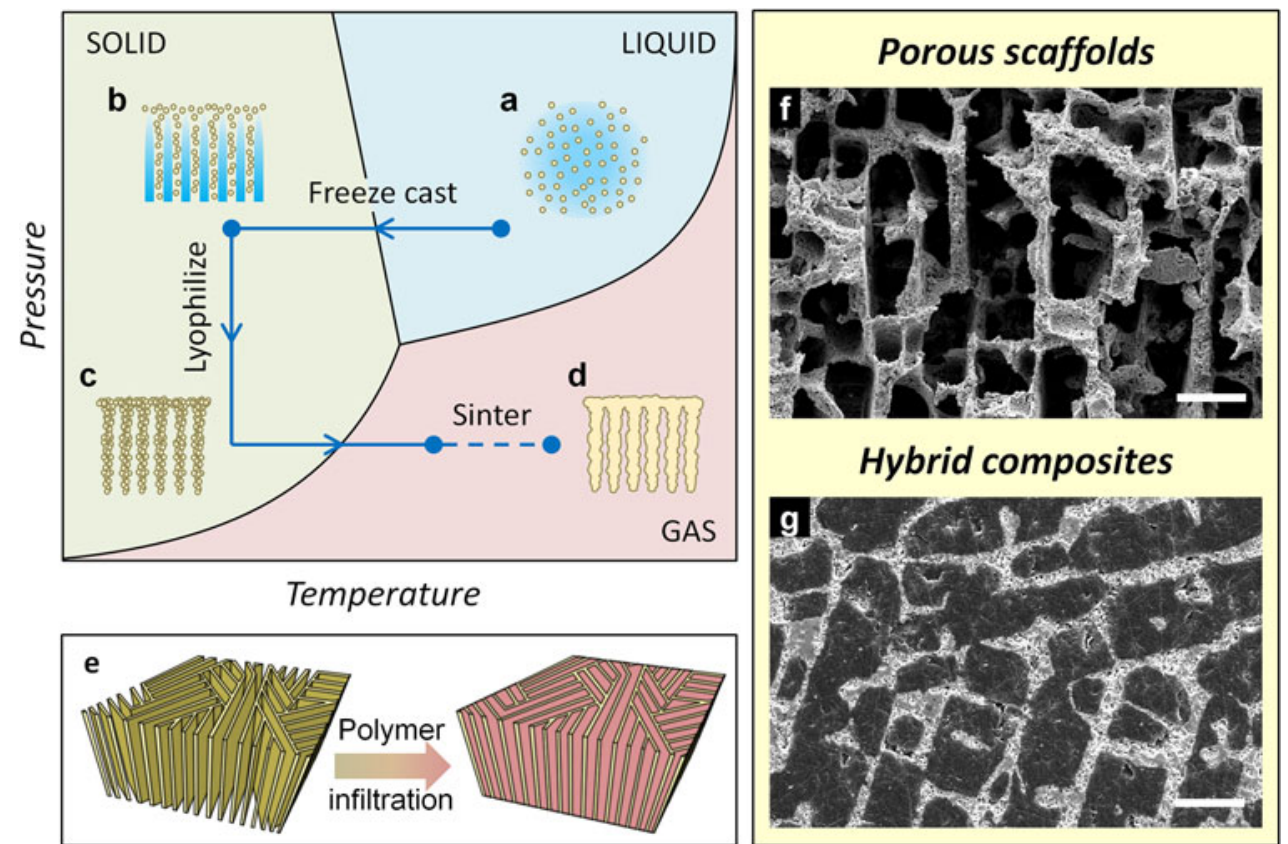

Fig. 1. (a-d) Phase diagram of water showing the path of processing steps involved in freeze casting porous ceramics: (a) slurry preparation and mixing; (b) freezing casting; (c) lyophilizing; (d) sintering. (e) Schematic of polymer infiltration, impregnating a porous scaffold (right) with a polymer phase to fabricate a hybrid composite (left). (f) Micrograph of a porous zirconia scaffold fabricated by freeze casting. (g) Micrograph of a hybrid zirconia-epoxy composite after polymer infiltration. Scale bars: $20 \mu \mathrm{m}$.

Figure 1e shows a schematic of this process. A variety of different polymer infiltration techniques includes polymer melt immersion, ${ }^{23}$ polymersolvent evaporation, ${ }^{24-28}$ in situ polymerization, ${ }^{19-21,29-32}$ particle centrifugation, ${ }^{33}$ and chemical vapor deposition. ${ }^{34-36}$ In situ polymerization is the most popular method used to impregnate porous scaffolds with polymers. In this method, a liquid monomer and catalyst are forced into the pores of a ceramic scaffold under vacuum and subsequently polymerized. Figure $1 \mathrm{f}-\mathrm{g}$ show micrographs of a porous zirconia scaffold (Fig. 1f) and a hybrid zirconia-epoxy composite (Fig. 1g) synthesized in this manner. Interpenetrating, bi-continuous composites, such as those shown in Fig. 1g, are generally stronger and tougher than composites composed of a polymer matrix containing randomly dispersed ceramic particles. ${ }^{20}$

There are a variety of potential applications for porous ceramics and hybrid composites fabricated by freeze casting. Biomimetic materials, such as structural composites ${ }^{19-22,29-31,37,38}$ that may be useful as high-performance components in industries ranging from aerospace to automotive manufacturing and potential bone replacements ${ }^{12,13,19,31,39-59}$ are most encouraging and are the primary focus of this article. Other potential applications for freeze-cast materials with complex shapes and designer microstructures include separation filters, insulators, sensors, electrodes, catalyst supports, fuel cells, and piezoelectric devices. ${ }^{14-17}$

\section{MICROSTRUCTURAL CONTROL}

Freeze casting is an exciting materials processing technique because it allows for precise microstructural control of porous materials with complex shapes and sizes. The theory behind freeze casting was recently explicated by Zhang et al., ${ }^{60}$ Deville et al., ${ }^{61-63}$ and Wegst et al., ${ }^{59}$ where constitutional supercooling drives instabilities (or undulations) in the freezing front that lead to the nucleation and growth of uniformly distributed, interconnected ice crystals. During solidification, the thermodynamic free energy of the system governs the phenomena of particle entrapment or rejection by the approaching freezing front ${ }^{59}$ :

$$
\Delta \sigma_{0}=\sigma_{\mathrm{ps}}-\left(\sigma_{\mathrm{pl}}+\sigma_{\mathrm{sl}}\right)
$$

where $\Delta \sigma_{0}$ is the change in free energy of the system, and $\sigma_{\mathrm{ps}}, \sigma_{\mathrm{pl}}$, and $\sigma_{\mathrm{sl}}$ are the surface energies between the particle-solid, particle-liquid, and solid-liquid interfaces, respectively. If the energy of the particle-solid interface is lower than the sum of the energies at the particle-liquid and solid-liquid surfaces, then the change in the system free energy is negative $\left(\Delta \sigma_{0}<0\right)$ and the particle is entrapped. ${ }^{59}$ If the change in the system free energy is positive $\left(\Delta \sigma_{0}>0\right)$ the particle is rejected. ${ }^{59}$ Particle entrapment and rejection can be controlled by changing the slurry properties and freezing conditions, resulting in finely-tuned pore morphologies and microstructural features. 
Four different solvents commonly used in freeze casting are water, camphene, camphor-naphthalene, and tert-butyl alcohol, ${ }^{14}$ each generating characteristic pore architectures, respectively: lamellar (Fig. 2a), ${ }^{41}$ cellular (Fig. 2b) ${ }^{64}$ dendritic (Fig. 2c) ${ }^{65}$ and prismatic (Fig. 2d). ${ }^{66}$ Manipulating the freezing-front velocity and temperature gradient of the liquid slurry changes the spacing and thickness of the scaffold walls. ${ }^{19,67}$ Empirically, it was shown that lamellar wall spacing $(\lambda)$ decreases as the velocity $(v)$ of the freezing-front increases (for aqueous slurries), following a power relationship:

$$
\lambda \propto \frac{1}{v^{m}}
$$

where $m$ is dependent on the particle size. ${ }^{67}$ Furthermore, the size and concentration of the particles in a liquid slurry can alter the homogeneity, porosity, and surface roughness of the resulting scaffolds. Increasing the solid loading (i.e., concentration of particles) decreases the resulting scaffold porosity. ${ }^{68}$ Decreasing the particle size generally increases the intricacy and uniformity of the microstructural features that directly replicate the tiny dendritic ice structures. ${ }^{69}$
Other slurry properties, such as $\mathrm{pH}$, viscosity, eutectic temperature, osmotic pressure, and surface tension, influence the behavior of the freezing vehicle. ${ }^{58,59,61,68,70-76}$ Changing these properties is generally accomplished by adding various liquid modifiers. Rheological properties, such as $\mathrm{pH}$ and viscosity, show strong correlations to the resulting microstructure and mechanical properties of freezecast scaffolds. ${ }^{58} \mathrm{Fu}$ et al. ${ }^{43}$ and Munch et al. ${ }^{71}$ used additives, such as dioxane (Fig. 2e), glycerol (Fig. 2f), sucrose, sodium chloride, citric water, or ethanol, to modify the microstructures (e.g., lamellar or cellular), surface roughness (e.g., faceted or dendritic), and interlamellar bridging of freeze-cast scaffolds by changing the eutectic phase diagram of the colloidal suspensions. Our group (UCSD) (unpublished work) is investigating the effects of isopropanol, which results in elongated lamellar pores with periodic surface roughness and thick mineral bridging (Fig. 2g). Pekor et al. ${ }^{72,73}$ demonstrated that soluble polymers commonly used as plasticizers, such as polyethylene glycol and polyvinyl alcohol, have a significant effect on the degree of constitutional supercooling, which affects pore size and secondary dendrite spacing. Deville et al. ${ }^{77}$
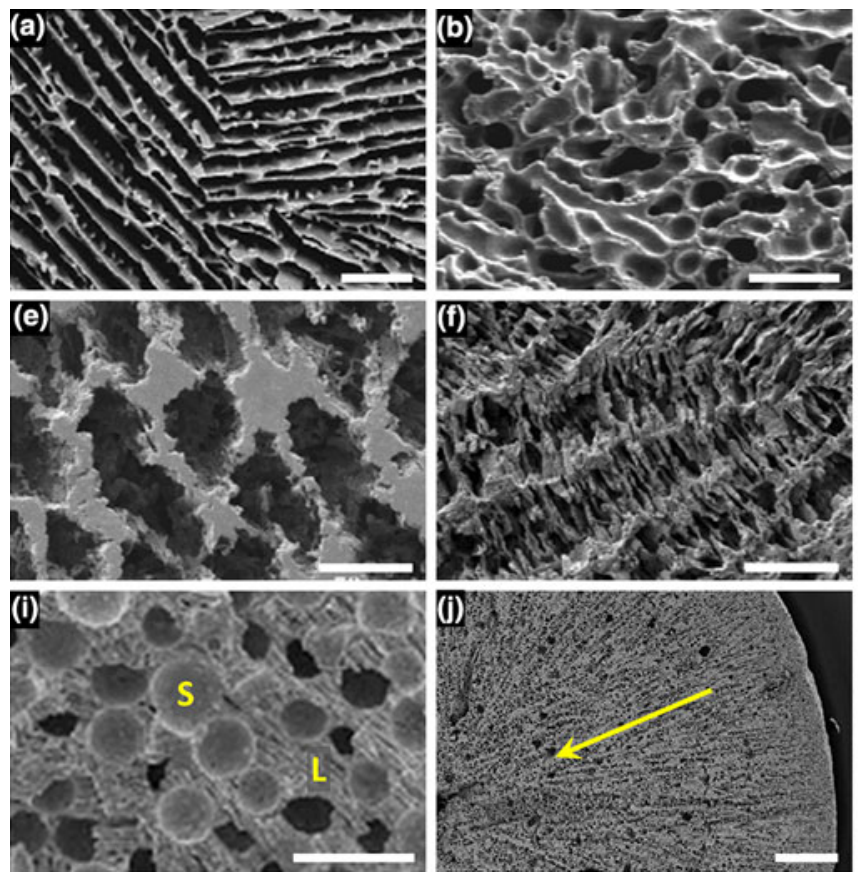
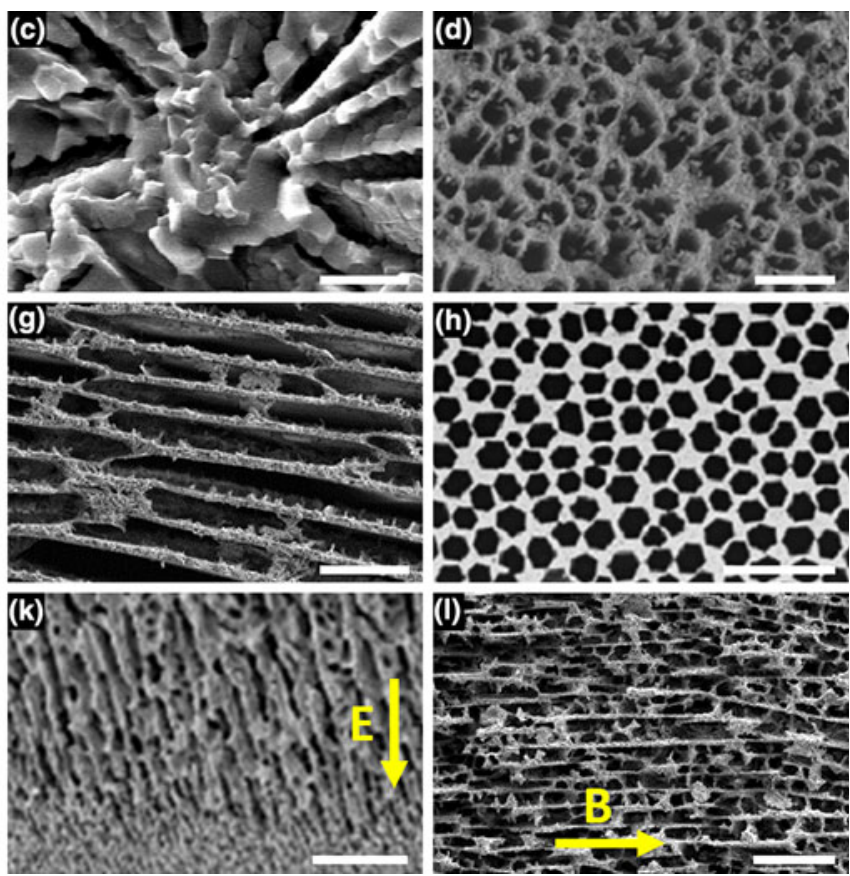

Fig. 2. Effect of different freezing vehicles (a-d), additives (e-i), and freezing conditions (j-l) on microstructure of different ceramic scaffolds: (a) hydroxyapatite in water, resulting in lamellar pores ${ }^{41}$; (b) alumina in camphene, resulting in cellular pores ${ }^{64}$; (c) alumina in camphor-naphthalene, resulting in dendritic channels ${ }^{65}$; (d) lead zirconate titanate in tert-butyl alcohol, resulting in prismatic pores ${ }^{66}$; (e) hydroxyapatite with 60 wt.\% dioxane, resulting in cellular pores ${ }^{43}$; (f) hydroxyapatite with 20 wt.\% glycerol, resulting in dendritic pores ${ }^{43}$; (g) titania with 9 wt.\% isopropanol, resulting in elongated lamellar pores [unpublished work]; (h) Yttria-stabilized zirconia with $18 \mathrm{~g} / \mathrm{L}$ zirconium acetate, resulting in faceted polyhedral pores ${ }^{77}$; (i) hydroxyapatite with PMMA pore formers, resulting in large spherical (S) pores and small lamellar (L) pores ${ }^{81}$; (j) hydroxyapatite with radial cooling, resulting in radially aligned pores (arrow indicates direction of temperature gradient) ${ }^{49} ;(\mathrm{k})$ alumina with an electric field applied parallel to the freezing direction, resulting in dense/porous bi-layers (arrow indicates direction of electric field) ${ }^{87}$; (I) titania with a magnetic field applied perpendicular to the freezing direction, resulting in pore alignment in multiple directions (arrow indicates direction of magnetic field; ice growth out of page). ${ }^{88}$ Scale bars: (a) $150 \mu \mathrm{m}$; (b) $50 \mu \mathrm{m}$; (c) $10 \mu \mathrm{m}$; (d) $200 \mu \mathrm{m}$; (e) $50 \mu \mathrm{m}$; (f) $50 \mu \mathrm{m}$; (g) $50 \mu \mathrm{m}$; (h) $25 \mu \mathrm{m}$; (i) $500 \mu \mathrm{m}$; (j) 1 mm; (k) $50 \mu \mathrm{m}$; and (l) $100 \mu \mathrm{m}$. Adapted from Refs. [41, 43, 49, 64-66, 77, 81, 87, 88]. 
used zirconium acetate, a salt with unique icestructuring properties, to limit the incorporation of water molecules into growing ice crystals, resulting in faceted polyhedral structures (Fig. 2h). Several research groups have demonstrated that sacrificial pore-formers, such as polymer beads, sponges or salts, added to the slurry before freezing and removed after lyophilization by heating or dissolving with appropriate solvents create complex pore architectures with varied morphologies (Fig. 2i). ${ }^{56,78-82}$

Modifying the freeze conditions is another alternative to control the microstructures of freeze-cast scaffolds. Munch et al. ${ }^{71}$ showed that patterning the freezing surface can manipulate the long-range ordering of ice lamellae by controlling the initial direction of nucleation. Deville et al. ${ }^{67}$ and Waschkies et al. ${ }^{83}$ used double-sided cooling to more precisely control the temperature gradient. Moon et al., ${ }^{84}$ Macchetta et al., ${ }^{49}$ and Koh et al. ${ }^{85}$ demonstrated the concept of radial cooling to construct porous ceramics with radial channel alignment (Fig. 2j). Jung et al. ${ }^{44}$ used sequential solid loading to create titanium scaffolds with a gradient in porosity and pore sizes. Koh et al. ${ }^{86}$ fabricated dense/porous bilayered ceramics with camphene, by freezing the bottom surface, while exposing the top surface of the slurry to air for controlled solvent evaporation. Zhang et al. ${ }^{87}$ fabricated dense/porous bilayered ceramics by applying an electric field during freezing (Fig. 2k). Porter et al. ${ }^{88}$ applied a magnetic field perpendicular to the ice growth direction in a uniaxial freezing device to align lamellar microstructures in two directions: parallel to the freezing direction and the magnetic flux path (Fig. 21).

\section{BIOMIMICRY}

\section{Mimicking Bone and Nacre}

Biomimetic materials are artificial materials that mimic the structure, function, or properties of natural biological materials. ${ }^{89}$ Two of the most celebrated and extensively studied natural materials are bone and nacre. ${ }^{2,3}$ Both natural materials are lightweight structural composites composed of inorganic minerals embedded in an organic matrix. $^{2,3}$ Many of the complex architectural features observed in bone and nacre provide them simultaneous strength and toughness, properties that are generally considered mutually exclusive. ${ }^{90}$ Freeze casting is a unique way to fabricate synthetic architectural features that emulate the strengthening and toughening mechanisms found in a variety of natural materials. For example, Fig. 3 compares micrographs of natural bone and nacre to artificial materials fabricated by freeze casting.

Bone is composed of $\sim 67$ wt.\% hydroxyapatite (HA) minerals embedded in an organic matrix of type I collagen. ${ }^{91}$ It exists in two main forms: cortical (or compact) bone and cancellous (or spongy) bone. ${ }^{91}$ At the microstructural level, cortical bone is composed of osteons (Fig. 3a), which consist of dense (5-10\% porosity) concentrically oriented lamellar sheets that surround small vascular channels and lacuna spaces $\sim 10-50 \mu \mathrm{m}$ in diameter. ${ }^{31,92}$ Cancellous bone (Fig. $3 \mathrm{~b}$ ), on the other hand, is highly porous (75-85\% porosity) and consists of trabecular struts that surround large pores $\sim 100-500 \mu \mathrm{m}$ in diameter. ${ }^{31,93}$ Figure $3 \mathrm{c}$ shows an artificial scaffold fabricated by freeze casting on a concentrically patterned surface that reflects the natural architecture of an osteon. ${ }^{19}$ Figure $3 d$ shows an artificial scaffold fabricated by a modified method that combines freeze gel casting and the polymer sponge technique, mimicking the trabecular architecture of cancellous bone. ${ }^{56}$

Nacre is composed of $\sim 95$ wt.\% aragonite platelets (or tiles) embedded in an organic matrix of chitin. ${ }^{94}$ Commonly described as a "brick-and-mortar" structure, the aragonite platelets are "bricks" that are self-assembled and "glued" together by the chitin biopolymer matrix. ${ }^{95}$ By freeze casting thin alumina platelets, Hunger et al. ${ }^{96}$ showed that shear flow induced by ice growth aligns platelets with their long dimension parallel to the freezing direction. This resulted in scaffolds with nacre-like microstructures having a higher toughness, yield strength, and Young's modulus than similar scaffolds composed of spherical particles. ${ }^{96}$ Excluding the organic matrix, nacre primarily relies on two intrinsic toughening mechanisms: mineral bridges (Fig. 3e) and surface asperities (Fig. 3f). ${ }^{95,97,98}$ Figure $3 \mathrm{~g}$ shows a magnified micrograph of a single mineral bridge connecting two adjacent lamellae formed during the sintering stage after freeze casting. ${ }^{20}$ Figure $3 \mathrm{~h}$ shows surface roughness asperities fabricated by freeze casting with the addition of sucrose. ${ }^{20}$ As previously mentioned (refer to Fig. 2), the density and thickness of mineral bridges as well as the surface roughness of lamellar walls can be tailored by changing the slurry properties and freezing conditions.

The organic matrix is, perhaps, the most important toughening mechanism in bone and nacre. For instance, the tensile strength in nacre (perpendicular to the layered structure) is $\sim 4.2 \mathrm{MPa}$, compared to that of deproteinized nacre having a strength of $\sim 0.33 \mathrm{MPa}{ }^{99}$ Even though the organic matrix accounts for only 5 vol.\% of nacre, when it is removed the strength of nacre is reduced by $\sim 92 \% .{ }^{99}$ Similarly, the compressive strength and stiffness of cortical bone (as reported for mature bovine femur bone in the longitudinal direction) decreases from $\sim 120 \mathrm{MPa}$ and $\sim 22 \mathrm{GPa}$, respectively, to $\sim 24 \mathrm{MPa}$ and $\sim 9 \mathrm{GPa}$ when the organic matrix is removed by deproteinization. ${ }^{92}$ Therefore, it is no wonder several research groups focus on freeze casting and subsequent polymer infiltration to fabricate hybrid inorganic-organic composites. ${ }^{19-22,29-31,37,38}$ 

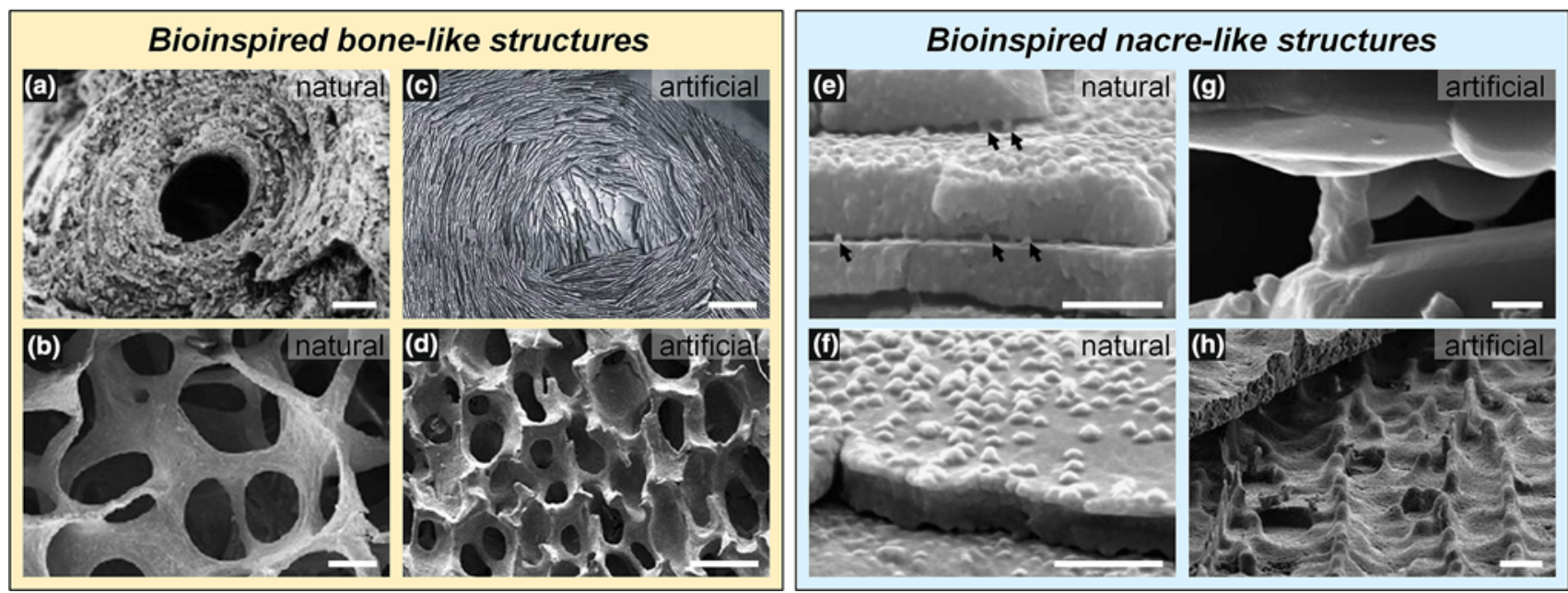

Fig. 3. Micrographs of natural materials and artificial freeze-cast structures inspired by bone (left) and nacre (right): (a) natural osteon found in cortical bone ${ }^{91}$; (b) natural cancellous bone scaffold ${ }^{103}$; (c) artificial freeze-cast scaffold that mimics the architecture of an osteon ${ }^{19}$; (d) artificial freeze-cast scaffold that mimics the architecture of cancellous bone ${ }^{56}$; (e) natural mineral bridges found in abalone nacre ${ }^{97}$; (f) natural surface asperities found in abalone nacre ${ }^{95} ; \mathrm{g}$ ) mineral bridge between adjacent lamellae of an artificial freeze-cast scaffold ${ }^{20}$; (h) surface roughness asperities on an artificial freeze-cast scaffold. ${ }^{20}$ Scale bars: (a) $20 \mu \mathrm{m}$; (b) $250 \mu \mathrm{m}$; (c) $500 \mu \mathrm{m}$; (d) $50 \mu \mathrm{m}$; (e) $500 \mathrm{~nm}$; (f) $500 \mathrm{~nm}$; (g) $600 \mathrm{~nm}$; and (h) $10 \mu \mathrm{m}$. Adapted from Refs. [19, 20, 56, 91, 95, 97, 103].

\section{Hybrid Composites}

To date, Tomsia and co-workers ${ }^{19-22}$ have developed the most notable hybrid composites by freeze casting ceramic scaffolds and subsequently infiltrating metals or polymers. Artificial aluminapolymethylmethacrylate $\left(\mathrm{Al}_{2} \mathrm{O}_{3}\right.$-PMMA) composites were shown to have lamellar and "brick-and-mortar" structures similar to natural nacre that range from $\sim 36$ vol. $\%$ up to $\sim 80$ vol. $\%$ ceramic phase. ${ }^{20,21}$ These composites exhibit a bending strength (up to $\sim 210 \mathrm{MPa}$ ) and crack growth fracture toughness (up to $\sim 32 \mathrm{MPa} \mathrm{m}^{1 / 2}$ ) that 0 nacre (Fig. 4 ). ${ }^{20,21}$ The superior mechanical properties observed in the artificial nacre-like composites are, in part, due to the use of high-performance engineering materials (e.g., $\mathrm{Al}_{2} \mathrm{O}_{3}$ and PMMA), rather than the relatively weak constituents that make up nacre (i.e., aragonite and chitin). The bicontinuous interpenetrating networks of the ceramic and polymer phases, along with the anisotropic directional alignment induced by freeze casting, enhance the strength and toughness of these hybrid composites. Furthermore, chemical grafting of the PMMA to the $\mathrm{Al}_{2} \mathrm{O}_{3}$ surfaces promoted strong covalent bonding between the two phases, which helped protect against interfacial shear and subsequent delamination. ${ }^{20,21,30,38}$

\section{Bone Replacements}

Several attempts to fabricate freeze-cast scaffolds for bone replacement materials have been reported. $^{12,13,19,31,39-59}$ Porous HA scaffolds developed by Deville et al. ${ }^{41}$ have an interconnected porosity with lamellar pores $10-50 \mu \mathrm{m}$ wide and high compressive strengths up to $145 \mathrm{MPa}$, nearly

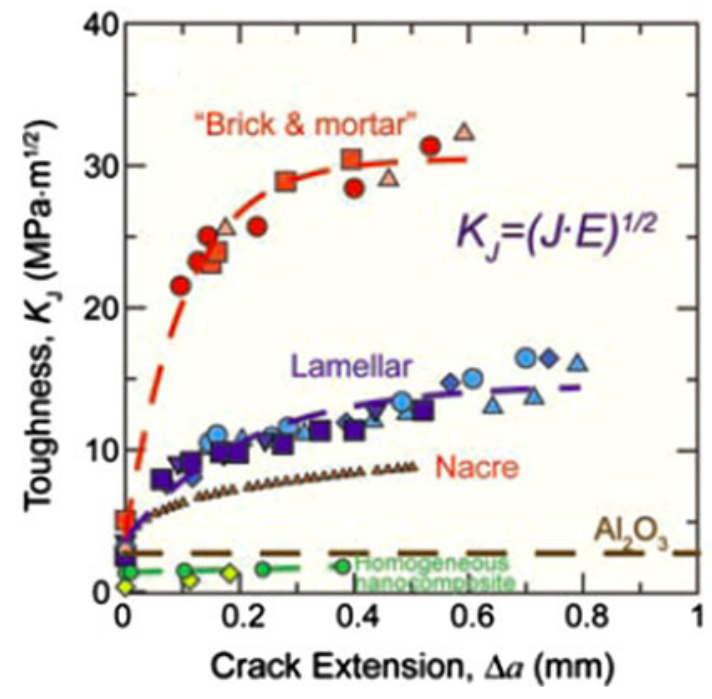

Fig. 4. Crack growth fracture toughness (R-curve) of artificial brickand-mortar and lamellar composites compared to natural nacre and homogeneous nanocomposites consisting of randomly dispersed nanoparticles. All artificial composites were composed of $\mathrm{Al}_{2} \mathrm{O}_{3}$ and PMMA. ${ }^{20}$ Taken from Ref. [20].

that of cortical bone (Fig. 5). HA is an ideal material for artificial bone replacements because it is the primary mineral constituent in natural bone. Fu et al. ${ }^{42}$ proved that freeze-cast HA with lamellar $(\sim 25 \mu \mathrm{m}$ wide) and cellular ( $\sim 100 \mu \mathrm{m}$ in diameter $)$ architectures are able to support the proliferation of preosteoblastic cells (MC3T3-E1) in vitro. By investigating the two types of pore architectures, it was demonstrated that the scaffolds with cellular pores showed far better cell proliferation, differentiation, and migration, suggesting that larger pores $(>50 \mu \mathrm{m})$ are 


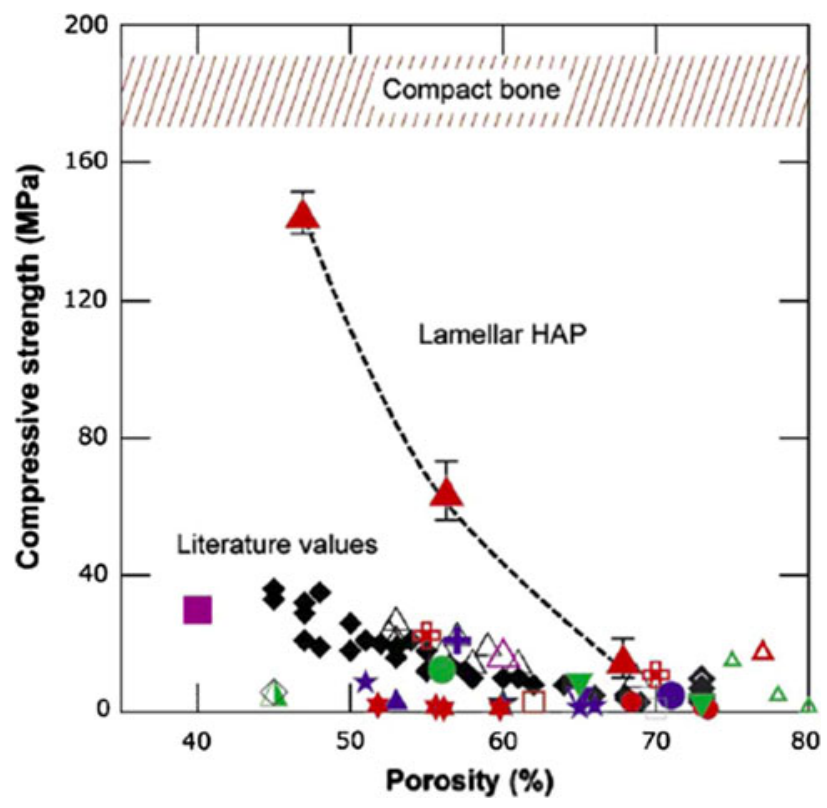

Fig. 5. Maximum compressive strength of freeze-cast lamellar hydroxyapatite (HAP) scaffolds compared to other HAP scaffolds reported in literature. ${ }^{41}$ Taken from Ref. [41].

desirable for adequate bone ingrowth. ${ }^{42,100,101}$ Hybrid composites are another alternative for bone replacement materials with higher strength and toughness. ${ }^{19,31}$ The use of a biodegradable polymer as the impregnated phase may allow the organic phase to degrade over time so that porosity is created in situ to promote new bone ingrowth. ${ }^{19,31}$

\section{Magnetic Freeze Casting}

Figure 6 shows a recent innovation of freeze casting inspired by the narwhal (Fig. 6a). Applying an external rotating magnetic field, Porter et al. ${ }^{88}$ developed composite ceramic scaffolds with spiraling structures (Fig. 6c) that mimic its tusk (Fig. 6b). Initially, small concentrations of magnetite $\left(\mathrm{Fe}_{3} \mathrm{O}_{4}\right)$ nanoparticles were added as magnetic attractants to aqueous slurries containing different nonmagnetic ceramic powders (i.e., $\mathrm{HA}, \mathrm{ZrO}_{2}, \mathrm{Al}_{2} \mathrm{O}_{3}$, and $\mathrm{TiO}_{2}$ ). The spiraling structures were generated by the uniaxial solidification of ice, which trapped $\mathrm{Fe}_{3} \mathrm{O}_{4}$ nanoparticles (brown spirals seen in Fig. 6c) attracted to the rotating magnetic field in their respective positions as ice crystals grew along the length of the cylindrical samples. By changing the magnetic field strength, rotation, and ceramic powder precursors, a variety of composite scaffolds was fabricated with different material properties and encouraging results. ${ }^{88}$

Under a static magnetic field, $\mathrm{TiO}_{2}-\mathrm{Fe}_{3} \mathrm{O}_{4}$ scaffolds showed homogeneous microstructural organization with enhanced strength and stiffness in directions parallel to the magnetic flux path. ${ }^{88} \mathrm{As}$ seen in Fig. 6d, the strength and stiffness more than doubled (in the magnetic field direction) with the
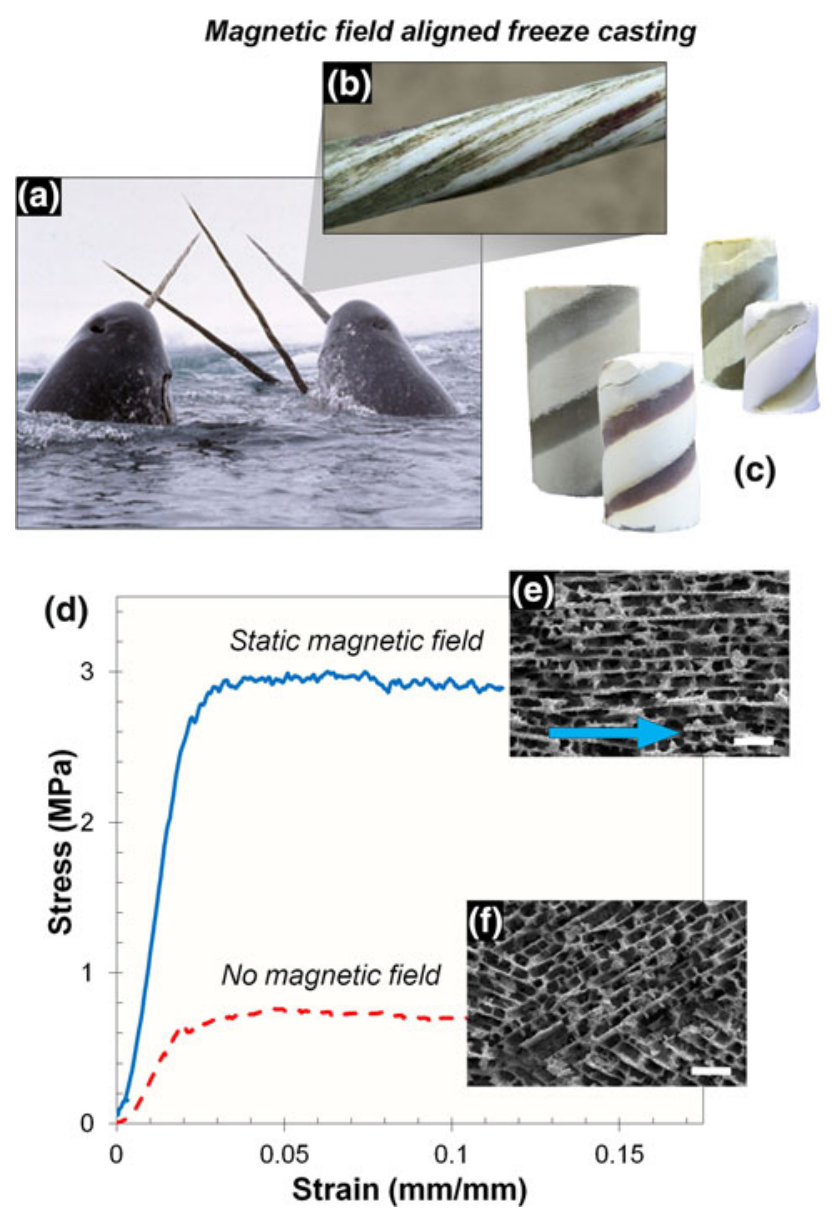

Fig. 6. Magnetic field aligned freeze casting inspired by the narwhal tusk: (a) image of several male narwhals [Nat Geo]; (b) magnified image of the narwhal tusk, showing its spiraling nature [Sci for Kids]; (c) magnetic field aligned freeze cast zirconia-magnetite (left) and alumina-magnetite (right) scaffolds before (back) and after (front) sintering - the spiraling magnetite phase (brown) was attracted to the poles of a rotating magnetic field $(0.12 \mathrm{~T}, 0.05 \mathrm{rpm})$ propagating perpendicular to the freezing direction in a uniaxial freezing device; (d) representative stress-strain curves of titania-magnetite scaffolds freeze cast under two conditions: (e) static magnetic field $(0.12 \mathrm{~T})$ and (f) no magnetic field. The samples in (d) were compressed perpendicular to the freezing direction and parallel to the magnetic field direction. The blue arrow in (e) represents the magnetic field direction. Scale bars: $50 \mu \mathrm{m}$. Adapted from Refs. [88, 104, 105].

addition of a static magnetic field (Fig. 6e) over identical samples fabricated with no magnetic field (Fig. 6f). The enhanced mechanical properties arise from the directional alignment of pore channels induced by the magnetic field. ${ }^{88}$ Potential applications for magnetic field aligned freeze casting include: spiral-reinforced structures with exceptional torsional rigidity, structural alignment of high aspect ratio nanoparticles to create "nanobridges" between adjacent lamellae for increased strength and toughness, or local two-dimensional and threedimensional reinforced structures, such as those described by Erb et al. ${ }^{102}$ 


\section{CONCLUSIONS}

Natural structural materials, such as bone and nacre, are excellent examples of how microstructure and architectural organization across multiple length scales influence mechanical properties. Mimicking the various strengthening and toughening mechanisms observed in nature led to the development of novel lightweight, high-performance materials. Freeze casting is a popular method to fabricate biomimetic materials that emulate the microstructural features of natural biological materials. Intricate microstructural control of porous scaffolds and hybrid composites is possible by altering the slurry properties and freeze conditions during the freeze casting process. Bioinspired applications for freeze casting include hybrid inorganic-organic composites for structural components that mimic nacre, porous ceramic scaffolds for bone replacements that mimic bone, and magnetic field aligned freeze casting for multidirectional alignment inspired by the narwhal tusk.

\section{ACKNOWLEDGEMENTS}

We are particularly thankful to Dr. A.P. Tomsia for sharing with us the technology for freeze casting at the Lawrence Berkeley National Laboratory. Professor E.A. Olevsky and Dr. Y.-S. Lin conducted systematic experiments at San Diego State University that were helpful in our understanding of the freeze casting process. Dr. E. Novitskaya and Ms. M.I. Lopez contributed their knowledge of the material properties of bone and nacre. Support by the National Science Foundation, Division of Materials Research, Ceramics and Biomaterials Program, 1006931, is gratefully acknowledged.

\section{REFERENCES}

1. M.A. Meyers, J. McKittrick, and P.-Y. Chen, Science 339, 773 (2013).

2. P.Y. Chen, J. McKittrick, and M.A. Meyers, Prog. Mater Sci. 57, 1492 (2012).

3. M.A. Meyers, P.Y. Chen, A.Y.M. Lin, and Y. Seki, Prog. Mater Sci. 53, 1 (2008).

4. Y.-Q. Li, T. Yu, T.-Y. Yang, L.-X. Zheng, and K. Liao, Adv. Mater. 24, 3426 (2012).

5. A. Sellinger, P.M. Weiss, A. Nguyen, Y.F. Lu, R.A. Assink, W.L. Gong, and C.J. Brinker, Nature 394, 256 (1998).

6. Z.Y. Tang, N.A. Kotov, S. Magonov, and B. Ozturk, Nat. Mater. 2, 413 (2003)

7. L.J. Bonderer, A.R. Studart, and L.J. Gauckler, Science 319, 1069 (2008).

8. P. Podsiadlo, A.K. Kaushik, E.M. Arruda, A.M. Waas, B.S. Shim, J.D. Xu, H. Nandivada, B.G. Pumplin, J. Lahann, A. Ramamoorthy, and N.A. Kotov, Science 318, 80 (2007).

9. S. Ludwigs, U. Steiner, A.N. Kulak, R. Lam, and F.C. Meldrum, Adv. Mater. 18, 2270 (2006).

10. J.-H. Lee, L. Wang, M.C. Boyce, and E.L. Thomas, Nano Lett. 12, 4392 (2012).

11. Q.A. Fu, E. Saiz, and A.P. Tomsia, Adv. Funct. Mater. 21 , 1058 (2011)

12. H. Seitz, W. Rieder, S. Irsen, B. Leukers, and C. Tille, J. Biomed. Mater. Res., Part B 74B, 782 (2005).

13. E. Munch, J. Franco, S. Deville, P. Hunger, E. Saiz, and A.P. Tomsia, JOM 60 (6), 54 (2008).

14. S. Deville, Adv. Eng. Mater. 10, 155 (2008).
15. M.C. Gutiérrez, M.L. Ferrer, and F. del Monte, Chem. Mater. 20, 634 (2008).

16. L. Qian and H.F. Zhang, J. Chem. Technol. Biotechnol. 86, 172 (2011).

17. W.L. Li, K. Lu, and J.Y. Walz, Int. Mater. Rev. 57, 37 (2012).

18. Q. Fu, M.N. Rahaman, F. Dogan, and B.S. Bal, J. Biomed. Mater. Res., Part B 86B, 514 (2008).

19. S. Deville, E. Saiz, R.K. Nalla, and A.P. Tomsia, Science 311, 515 (2006).

20. E. Munch, M.E. Launey, D.H. Alsem, E. Saiz, A.P. Tomsia, and R.O. Ritchie, Science 322, 1516 (2008).

21. M.E. Launey, E. Munch, D.H. Alsem, H.B. Barth, E. Saiz, A.P. Tomsia, and R.O. Ritchie, Acta Mater. 57, 2919 (2009)

22. M.E. Launey, E. Munch, D.H. Alsem, E. Saiz, A.P. Tomsia, and R.O. Ritchie, J. R. Soc. Interf. 7, 741 (2010).

23. F.J. Martinez-Vazquez, F.H. Perera, P. Miranda, A. Pajares, and F. Guiberteau, Acta Biomater. 6, 4361 (2010).

24. X. Miao, W.K. Lim, X. Huang, and Y. Chen, Mater. Lett. 59, 4000 (2005).

25. M. Peroglio, L. Gremillard, C. Gauthier, L. Chazeau, S. Verrier, M. Alini, and J. Chevalier, Acta Biomater. 6, 4369 (2010).

26. J. Russias, E. Saiz, R.K. Nalla, K. Gryn, R.O. Ritchie, and A.P. Tomsia, Mater. Sci. Eng. C-Biomimetic Supramol. Syst. 26, 1289 (2006)

27. S. Sharifi, Y. Shafieyan, H. Mirzadeh, S. Bagheri-Khoulenjani, S.M. Rabiee, M. Imani, M. Atai, M.A. Shokrgozar and A. Hatampoor, J. Biomed. Mater. Res., Part A 98A, 257 (2011).

28. H. Zou, S. Wu, and J. Shen, Chem. Rev. 108, 3893 (2008).

29. R. Chen, M.B. Johnson, K.P. Plucknett, and M.A. White, J. Mater. Res. 27, 1869 (2012).

30. A. Dutta and S.A. Tekalur, Mater. Des. 46, 802 (2013),

31. S. Lee, M. Porter, S. Wasko, G. Lau, P.-Y. Chen, E.E. Novitskaya, A.P. Tomsia, A. Almutairi, M.A. Meyers, and J. McKittrick, MRS Online Proceedings Library, vol. 1418 (2012).

32. G. Pezzotti, S.M.F. Asmus, L.P. Ferroni, and S. Miki, J. Mater. Sci. Mater. Med. 13, 783 (2002).

33. M.M. Porter, S. Lee, N. Tanadchangsaeng, M. Jaremko, J. Yu, M. Meyers, and J. McKittrick, Mechanics of Biological Systems and Materials, Vol. 5, ed. B.C. Prorok, F. Barthelat, C.S. Korach, K.J. Grande-Allen, E. Lipke, G. Lykofatitits, and P. Zavattieri (New York: Springer, 2013), pp. $63-71$.

34. H.-Y. Chen, Y. Elkasabi, and J. Lahann, J. Am. Chem. Soc. 128, 374 (2005)

35. Y. Elkasabi, H.Y. Chen, and J. Lahann, Adv. Mater. 18 , 1521 (2006).

36. J. Jang and B. Lim, Angew. Chem. Int. Ed. 42, 5600 (2003).

37. Z.-Y. Deng, H.R. Fernandes, J.M. Ventura, S. Kannan, and J.M.F. Ferreira, J. Am. Ceram. Soc. 90, 1265 (2007).

38. A. Dutta, A. Vanderklok, and S.A. Tekalur, Mech. Mater $55,102(2012)$

39. M. Azami, F. Moztarzadeh, and M. Tahriri, J. Porous Mater. 17, 313 (2010).

40. S. Blindow, M. Pulkin, D. Koch, G. Grathwohl, and K. Rezwan, Adv. Eng. Mater. 11, 875 (2009).

41. S. Deville, E. Saiz, and A.P. Tomsia, Biomaterials 27, 5480 (2006).

42. Q. Fu, M. Rahaman, B.S. Bal, and R. Brown, J. Mater. Sci. Mater. Med. 20, 1159 (2009).

43. Q. Fu, M.N. Rahaman, F. Dogan, and B.S. Bal, J. Biomed. Mater. Res. B 86, 514 (2008).

44. H.-D. Jung, S.-W. Yook, H.-E. Kim, and Y.-H. Koh, Mater. Lett. 63, 1545 (2009)

45. J.H. Kim, J.H. Lee, T.Y. Yang, S.Y. Yoon, B.K. Kim, and H.C. Park, Ceram. Int. 37, 2317 (2011).

46. E.-J. Lee, Y.-H. Koh, B.-H. Yoon, H.-E. Kim, and H.-W Kim, Mater. Lett. 61, 2270 (2007).

47. J.C. Li and D.C. Dunand, Acta Mater. 59, 146 (2011).

48. Y.-S. Lin, M.A. Meyers, and E.A. Olevsky, Adv. Appl. Ceram. 111, 269 (2012). 
49. A. Macchetta, I.G. Turner, and C.R. Bowen, Acta Biomater. 5, 1319 (2009).

50. K.K. Mallick, J. Am. Ceram. Soc. 92, S85 (2009).

51. K.K. Mallick, J. Winnett, W. van Grunsven, J. Lapworth, and G.C. Reilly, J. Biomed. Mater. Res., Part A 100A, 2948 (2012).

52. T. Moritz and H.-J. Richter, J. Am. Ceram. Soc. 89, 2394 (2006).

53. T. Moritz and H.J. Richter, J. Eur. Ceram. Soc. 27, 4595 (2007).

54. J.-H. Song, Y.-H. Koh, H.-E. Kim, L.-H. Li, and H.-J. Bahn, J. Am. Ceram. Soc. 89, 2649 (2006).

55. Y.M. Soon, K.H. Shin, Y.H. Koh, J.H. Lee, and H.E. Kim, Mater. Lett. 63, 1548 (2009).

56. T.Y. Yang, J.M. Lee, S.Y. Yoon, and H.C. Park, J. Mater. Sci. Mater. Med. 21, 1495 (2010)

57. B.H. Yoon, Y.H. Koh, C.S. Park, and H.E. Kim, J. Am. Ceram. Soc. 90, 1744 (2007).

58. Y. Zhang, K. Zhou, Y. Bao, and D. Zhang, Mater. Sci. Eng., C 33, 340 (2013).

59. U.G.K. Wegst, M. Schecter, A.E. Donius, and P.M. Hunger, Philos. Trans. R. Soc. A-Math Phys. Eng. Sci. 368, 2099 (2010).

60. H. Zhang, I. Hussain, M. Brust, M.F. Butler, S.P. Rannard, and A.I. Cooper, Nat. Mater. 4, 787 (2005).

61. S. Deville, E. Maire, G. Bernard-Granger, A. Lasalle, A. Bogner, C. Gauthier, J. Leloup, and C. Guizard, Nat. Mater. 8, 966 (2009).

62. S. Deville, E. Maire, A. Lasalle, A. Bogner, C. Gauthier, J. Leloup, and C. Guizard, J. Am. Ceram. Soc. 92, 2489 (2009).

63. S. Deville, E. Maire, A. Lasalle, A. Bogner, C. Gauthier, J. Leloup, and C. Guizard, J. Am. Ceram. Soc. 92, 2497 (2009).

64. K. Araki and J.W. Halloran, J. Am. Ceram. Soc. 88, 1108 (2005).

65. K. Araki and J.W. Halloran, J. Am. Ceram. Soc. 87, 2014 (2004).

66. R. Guo, C.A. Wang, and A.K. Yang, J. Am. Ceram. Soc. 94, 1794 (2011).

67. S. Deville, E. Saiz, and A.P. Tomsia, Acta Mater. 55, 1965 (2007).

68. S. Deville and G. Bernard-Granger, J. Eur. Ceram. Soc. 31, 983 (2011).

69. S. Deville, E. Maire, A. Lasalle, A. Bogner, C. Gauthier, J. Leloup, and C. Guizard, J. Am. Ceram. Soc. 93, 2507 (2010).

70. Q. Fu, M.N. Rahaman, F. Dogan, and B.S. Bal, J. Biomed. Mater. Res., Part B 86B, 125 (2008).

71. E. Munch, E. Saiz, A.P. Tomsia, and S. Deville, J. Am. Ceram. Soc. 92, 1534 (2009).

72. C. Pekor, B. Groth, and I. Nettleship, J. Am. Ceram. Soc. 93, $115(2010)$

73. C.M. Pekor, P. Kisa, and I. Nettleship, J. Am. Ceram. Soc. 91, 3185 (2008).

74. N.O. Shanti, K. Araki, and J.W. Halloran, J. Am. Ceram. Soc. 89, 2444 (2006).

75. J.L. Zou, Y. Zhang, and R.X. Li, Int. J. Appl. Ceram. Technol. 8, 482 (2011).

76. A. Lasalle, C. Guizard, E. Maire, J. Adrien, and S. Deville, Acta Mater. 60, 4594 (2012).
77. S. Deville, C. Viazzi, and C. Guizard, Langmuir 28, 14892 (2012).

78. J.H. Lee, H.J. Choi, S.Y. Yoon, B.K. Kim, and H.C. Park, J. Porous Mater. 20, 219 (2013).

79. T. Young Yang, W. Young Kim, S. Young Yoon, and H. Chae Park, J. Phys. Chem. Solids 71, 436 (2010).

80. J. Han, L. Hu, Y. Zhang, and Y. Zhou, J. Am. Ceram. Soc. 92,2165 (2009)

81. K.H. Zuo, Y. Zhang, Y.-P. Zeng, and D. Jiang, Ceram. Int. 37, 407 (2011).

82. A. Akkouch, Z. Zhang, and M. Rouabhia, J. Biomed. Mater. Res., Part A 96A, 693 (2011).

83. T. Waschkies, R. Oberacker, and M.J. Hoffmann, J. Am. Ceram. Soc. 92, S79 (2009)

84. J.W. Moon, H.J. Hwang, M. Awano, and K. Maeda, Mater. Lett. 57, 1428 (2003).

85. Y.H. Koh, E.J. Lee, B.H. Yoon, J.H. Song, H.E. Kim, and H.W. Kim, J. Am. Ceram. Soc. 89, 3646 (2006).

86. Y.-H. Koh, I.-K. Jun, J.-J. Sun, and H.-E. Kim, J. Am. Ceram. Soc. 89, 763 (2006).

87. Y.M. Zhang, L.Y. Hu, and J.C. Han, J. Am. Ceram. Soc. 92 1874 (2009).

88. M.M. Porter, M. Yeh, J. Strawson, T. Goehring, S. Lujan, P. Siripasopsotorn, M.A. Meyers, and J. McKittrick, Mater. Sci. Eng., A 556, 741 (2012).

89. P. Fratzl and J.R. Soc, Interface 4, 637 (2007).

90. R.O. Ritchie, Nat. Mater. 10, 817 (2011).

91. S. Weiner and H.D. Wagner, Ann. Rev. Mater. Sci. 28, 271 (1998).

92. E. Novitskaya, P.Y. Chen, S. Lee, A. Castro-Cesena, G. Hirata, V.A. Lubarda, and J. McKittrick, Acta Biomater. 7, 3170 (2011).

93. P.Y. Chen and J. McKittrick, J. Mech. Behav. Biomed. Mater. 4, 961 (2011).

94. A. Lin and M.A. Meyers, Mater. Sci. Eng., A 390, 27 (2005).

95. M.A. Meyers, A.Y.-M. Lin, P.-Y. Chen, and J. Muyco, J. Mech. Behav. Biomed. Mater. 1, 76 (2008).

96. P.M. Hunger, A.E. Donius, and U.G.K. Wegst, J. Mech. Behav. Biomed. Mater. 19, 87 (2008).

97. A.Y.-M. Lin, P.-Y. Chen, and M.A. Meyers, Acta Biomater. 4, 131 (2008).

98. A.Y.-M. Lin and M.A. Meyers, J. Mech. Behav. Biomed. Mater. 2, 607 (2009).

99. M.I. Lopez, P.E.M. Martinez, and M.A. Meyers, Acta Biomater. Unpublished work.

100. J. Lu, B. Flautre, K. Anselme, P. Hardouin, A. Gallur, M. Descamps, and B. Thierry, J. Mater. Sci. Mater. Med. 10, 111 (1999).

101. S.F. Hulbert, F.A. Young, R.S. Mathews, J.J. Klawitter, C.D. Talbert, and F.H. Stelling, J. Biomed. Mater. Res. 4, 433 (1970).

102. R.M. Erb, R. Libanori, N. Rothfuchs, and A.R. Studart, Science 335, 199 (2012).

103. X. Zhang, Q. Cai, H. Liu, B.C. Heng, H. Peng, Y. Song, Z. Yang, and X. Deng, Int. J. Oral Maxillofac. Surg. 41, 1330 (2012).

104. Narwhals: Arctic Whales With Super-Sensing Tusks. National Geographic News: National Geographic Society (1996), http://news.nationalgeographic.com/news/2005/12/ photogalleries/narwhals/. Accessed 14 March 2013.

105. A Whale's Amazing Tooth. Science News for Kids. Washington, D.C.: Society for Science and the Public (2013), http://www.sciencenewsforkids.org/2006/01/a-whalesamazing-tooth-2/. Accessed 14 March 2013. 